\title{
Practice-theoretical possibilities for social marketing: two fields learning from each other
}

\author{
F. Spotswood ${ }^{\mathrm{a}}$, T.Chatterton ${ }^{\mathrm{b}}$, Y. Morey ${ }^{\mathrm{a}}$, S. Spear ${ }^{\mathrm{a}}$ \\ ${ }^{a}$ Bristol Leadership and Change Centre, Faculty of Business and Law, University of the West of England, Bristol, UK \\ ${ }^{b}$ Department of Geography and Environmental Management, Faculty of Environment and Technology, , University \\ of the West of England, Bristol, UK.
}

\section{Introduction}

The goal of this paper is to contribute to a step change in the way social marketers think about the behaviours they seek to shift, how they plan to effect that change and the role of social marketing activities within a framework of behaviour change management. Our starting point is the recognition that human behaviour has a significant impact on large scale societal and global problems and that social marketing has a valuable contribution to make in its current form. However, we hope to add the benefit of learning from a different theoretical research stream that will support an increase in social marketing's ambition, scope, effectiveness and longevity, as well as adding to its kudos amongst other behaviour change disciplines. Lefebvre (2011) writes that: "In its most elemental form, social marketing is the application of marketing principles and techniques to foster social change or improvement" (p.57). It is the intention of this paper to wholly support this point but perhaps to help social marketing 'regain its soul' (Lefebvre, 2012) by helping accelerate the shift that is happening in the field; the surrendering of "the idea that social marketers are in the individual behavior change business" (ibid, p.122).

The role of individual behaviour change within broader 'social change or improvement' remains a topic of hot debate for reasons of political ideology, theoretical sense and practical effectiveness. It remains contested, as Hargreaves (2011) emphasises, to what extent sustainable consumption, for example, is "within the capacity of individual agents to bring about alone" (p.80). Welch (2016, p.240) elucidates:

“Conventional behaviour change strategies, primarily influenced by social psychology and economics...draw on an implicit model of behaviour, which assumes individuals' capacity to achieve change, and emphasises the deliberative character of behaviour... [T]his model structurally overestimates the role of choice in routine behaviour and fundamentally underestimates the extent to which individuals' autonomous action is constrained by infrastructures and institutions, by collective conventions and norms, and by access to resources."

The 'unsophisticated' (Butler et al., 2014), voluntarist approach of much contemporary social marketing is politically appealing in a neoliberal society (Shove, 2014) and the hegemony of the 
approaches which fall within this 'individualist' bracket can be "attributable to the priorities and philosophies of the governments that fund them" (Lefebvre, 2011, p.57). Neoliberal governance frames citizenship through a set of values and expectations which entail, on the one hand, the freedom, right, and even duty to consume, and, on the other, the expectation to engage in the self-regulation of consumption practices (Riley et al., 2012). The neoliberal golden rule is to avoid restricting the activities of corporate entities or to constrain through regulation the freedom of its citizens, to avoid the criticism of being a 'nanny state' (French, 2009).

The main alternative to individualism, particularly in public health, has been through analysis of the wider 'social determinants' of inequality; housing, work, transport, services, welfare, agriculture and food, sanitation and education (Bambra et al., 2010; Marmot et al., 2010). Social marketing commentary has noted repeatedly that efforts should target 'upstream', i.e. these wider determinants (Lefebvre, 2011). However, this language can be interpreted as dualistic; fixed on either changing individual behaviours or the wider determinants which underpin them at a population level. This dualistic conceptualisation of social change quickly reaches its limitations because structures and agency are interrelated. Neither agency nor structure can solely explain the habitual behaviours into which societies are locked (Butler et al., 2014), like eating and energy use patterns (Spaargaren, 2003; Warde et al., 2007). There are numerous theoretical solutions to the dualism problem, and although others are available (e.g. Actor Network Theory), practice theory (PT) has been becoming increasingly popular in the field of sustainability. PT is particularly characterised by being "not dependent on presumptions about the primacy of individual choice or action" (Warde, 2005, p.134). This paper presents a practice-theoretical understanding of how social change occurs, and seeks to offer a starting point for discussion about how social marketers' can create positive change to embedded routines that cannot easily be explained or overcome through a reliance on either individual change or societal structures alone.

Our attempt here is to strengthen the contribution that social marketing already makes to behaviour change, and not to add to the growing critique of the discipline. As such we take a pragmatic approach and attempt to draw on practice theory to bolster the social marketing total process planning model. We intend firstly to add to the growing ambition of social marketing that it can do more than just change behaviour but can transform "collective conventions" (Shove, 2014, p.421) - culturally ingrained ways of doing. Secondly, we aim to frame the contribution of social marketing within a transdisciplinary model of behaviour change where social marketing has a distinct and valuable role within a much broader community of behaviour change approaches. 


\section{Critique of social marketing}

Although there has been wide ranging criticism of social marketing (Truong, 2014), and much work to expand the field's focus (Domegan et al., 2016; Gordon et al., 2010), this paper seeks to respond to the ongoing assertions that SM is overly downstream and individualistic (Fry, 2014). Indeed, the hegemonic language in the social marketing literature is that it focuses "on people, their wants and needs, aspirations, lifestyle, freedom of choice..." (Lefebvre, 2011, p.58), and is about identifying "short term, concrete benefits that accrue to an individual as a consequence of their actions" (ibid, p.58). A recent systematic review of social marketing publications noted that over three quarters of social marketing articles "dealt with the downstream level. That is, they primarily focused on the delivery of individual behavior change" (Truong, 2014, p.22). Indeed, French (2009) boasts that social marketing "begins and ends with a focus on the individual" (p.262) and as Crawshaw (2013) explains that SM works "through encouraging people to make better choices within their own lives, regardless of the wider structural and relational determinants of health... To achieve this, the individual must be reflexive and rational in pursuit of their own health" (ibid, p.633). The downstream focus of social marketing emanates from the domination of psychological theories in use (Truong, 2014), denoting its historical intertwining with public health. Lefebvre (2011) points out that the narrow theoretical base "may place major constraints on what social marketing programs focus on (e.g. behaviors or social structures), their assumptions of underlying determinants (e.g. beliefs, intentions, self-efficacy, social determinants, social norms) and important outcomes (e.g. behavior versus policy change)" (p.60).

Criticisms of the theoretically-driven individualism of social marketing are based on three broad arguments; of ineffectiveness, lack of criticality and theoretical power. For large scale problems such as needing to achieve $>80 \%$ reductions in carbon emissions, the ineffectiveness of individualistic approaches is particularly apparent and has been commonly noted in the mobility and active travel arenas (Arnott et al., 2014; Bonsall, 2009). Even when significant changes are identifiable in energy consumption through individualist interventions, these are minimal in comparison to those which changed social or physical contexts for energy use (Tsang et al., 2012). Furthermore, individualism has been linked with widening inequality in energy reduction, as in health (Lorenc et al., 2013). Those who have capabilities to make early changes to their energy consumption due to surplus disposable income, higher education levels and lesser impact from structural inequalities, can often reap a double benefit from fiscal subsidies and the lower cost of self-generated energy (Chatterton et al., 2016).

Secondly, authors argue that approaches which rely on the capacity for individuals to make meaningful change fail to challenge social conventions, rather legitimising and reinforcing them (Shove, 2014). Criticism for individualist social marketing comes from within the discipline; that it presumes individuals have the power to change, despite the strength of organisational, 
political and material frameworks (Gordon et al., 2010; Hastings, 2009; 2014). From outside, practice theorists and others (e.g. Hargreaves, 2011; Røpke, 2009) argue that individualistic approaches fail to account for the inseparability of material and socio-cultural context from the performance of daily activities. An example is drawn from Griffin et al. (2009) who found that excessive peer group drinking and recreational drug use are deployed by some young people to resist the neoliberal focus on compulsory individualism.

Finally, authors have further noted that the failure of behaviour change activities to question the interrelationship of social framings and behaviour merely adds to the social reproduction of problematic activity in the sense that people "inculcate the world they encounter into their subjective mentalities" and then behave accordingly (Butler et al., 2014, p.5). In this sense, behaviour change activity can be inherently politically conformist (Raftopoulou and Hogg, 2009). Authors argue that behaviour and cause are not part of a linear explanation (Chatterton, 2016; Harrison and Davies, 1998) and that theories need to consider "social structures in relationship with embodied values and perspectives or dispositions" which configure behavioural patterns (Butler et al., 2014, p.14). Practice theory, introduced next, offers one such potential theoretical solution because it sidesteps the agency-structure debate and rather considers them as interrelated. We acknowledge that there are other theoretical innovations in behaviour change (e.g. Evans, 2008), but here focus on practice theory given the significant profile it is achieving (see www.demand.ac.uk).

\section{An introduction to practice theory}

Practice theory has been offered as a potential solution to the critiques of individualist behaviour change approaches which emphasise choice and decision making (Moloney and Strengers, 2014), and has begun to enter policy debates (Chatterton, 2011; Darnton and Evans, 2013; Darnton et al., 2011; Watson, 2016). Scholars of energy demand and consumption have taken the lead in exploring the potential of practice-theoretical thinking in terms of designing interventions and developing policies as opposed to simply academic understanding (Shove, 2010; Wilson and Chatterton, 2011), but progress is limited. This is due both to the predilection of government for tried-and-tested models that align with the overarching neoliberal political climate, and also to an academic tendency for failing to adapt theoretical approaches to the demands of contemporary policy and practitioner processes. Through a brief overview of practice theory, and by providing a suggested process for its practical application, this paper joins others in attempting to bridge this gap (Vihalemm et al., 2015).

Practices are the routine accomplishment of what people take to be 'normal' ways of life (Shove, 2010), which could be understood as the social arrangement of habits (see Shove (2012) for a discussion of 'habit' in practice theory). PT purports that social life is organised according to practices which people perform in the accomplishment of everyday activities, such as showering, eating meals, going to work, physical recreation and so on. Much of this activity is 
largely routinised by the people who perform it; there are sets of quietly understood and largely unspoken rules about how, when and with what these various activities are undertaken. We might eat a breakfast of cereal or toast upon waking, not because we 'decide' to do so, but because that is the shape that 'doing breakfast' takes. We can make choices within this context, to have eggs, say, but breakfast has meanings which are set and, importantly, reconstituted every day through its repeated performance by breakfasting actors.

This understanding of routinised patterns of practice as 'entities' performed by practitioners (Welch, 2016) is theoretically significant for the way behaviour is conceptualised and changed, and for how it differs from 'wider determinants' and 'individualist' approaches. The first is that the practice, not the individual, is the unit of study. Behaviour change starts with an understanding of how practices are constituted. There are various models seeking to label the components of practice but the clearest is the 3-elements model (Shove et al., 2012), according to which practices comprise material things ('stuff', equipment, infrastructure), competences (interchangeable with skills and know-how) and meanings (images, symbolism, understandings). Every practice arises from the configuration of these elements and an analysis of the elements can help identify the reasons a problematic practice, such as unhealthy snacking -has taken hold, as well as helping identify how the links between elements might be broken or changed. For the practice of commuting to become commonly performed by bicycle, requirements might include the competences of navigation and riding a bike; the material stuff of a bike, roads, panniers, helmet, locks and showers at work; and the meanings of cycling being acceptable at all career levels, supported by organisational leadership and by other road users (Spotswood et al., 2015). If the existing practice of cycle commuting falls short, as it does in the UK (DfT, 2014), then intervention will be required across multiple elements to significantly reconfigure how, and to what extent, it is undertaken.

Practice theory also purports that practices can be bundled inseparably together. For example, 'cycling to work' is bundled with working practices which determine scheduling and conventions around dress and status (Leonard et al., 2012). PT, by starting with the various interrelating practices which actors 'perform' or 'carry' (Reckwitz, 2002), allows for a more complete view of the way undesirable patterns of 'behaviour' arise and evolve and thus a more complete view of potentially multiple footholds for change (Hargreaves, 2011). There are often surprising connections between practices which would be missed in a conventional functionalist analysis (Hobson, 2002).

Practice theoreticians argue that there are two ways in which practices change; through the performers of routine who reconfigure a practice through their daily enactments, and from the outside (Warde, 2005), such as when the materials, meanings and competences within them change, or from evolution in neighbouring practices. Examples include smartphones (a material), which have afforded practice changes in music consumption, socialising and 
workforce practices; or anti-smoking campaigning which changed meanings around smoking and paved the way for regulation and ultimately wide-scale changes in tobacco consumption, pub-drinking and hospitality industry practices (Blue et al., 2016). Through looking at examples such as these, we begin to see the multiple intervention approaches which a practice approach might inspire.

The perspective afforded by PT also allows for a new way of viewing what is actually changing during behaviour change interventions, as Hargreaves' (2011) analysis of the 'environmental champions' programme demonstrates:

"A practice based approach broadens the perspective to include other mundane aspects of daily practice such as normally unquestioned skills and stuff that, whilst they would be ignored in more cognitivist accounts and may, on the face of it, have little to do with the environment, nonetheless appear central... [to the goals of the intervention]" (p.89).

Hargreaves (2011) found that the workers increasingly demonstrated an evolved collective understanding of the new 'rules' of recycling and energy saving. Similar shifts in socially negotiated procedures were noted by Sahakian and Wilhite (2014) in the London on Tap campaign, designed to increase the acceptability of ordering tap water in restaurants. In either case, traditional evaluations would not necessarily have captured the subtle and often slowerburn shifting of collective conventions which indicates practice change. In contrast, social marketing has been criticised for evaluation measures based on sales or ownership figures, which can be poor proxies for actual use, as shown by the low mosquito net deployment per ownership (Pulford et al., 2011; Thwing et al., 2008).

To conclude this section, we argue that social marketers could engage with practice theory as a way of helping the field move still further away from the historical focus on achieving discrete behaviour change. This is the ambition of a growing body of innovators in the SM field, and PT would allow for a framing of their ambition in terms of shifting collective convention (Shove, 2014) and routinised behavioural patterns (Southerton et al., 2011b), and provide a theoretical language for the conceptualising such projects.

\section{Limitations of practice theory}

Despite their acclaimed potential for shifting the perspective of policymakers and 'behaviour change' activities, particularly around sustainability (Chatterton, 2011), practice-theoretical contributions to understanding social change have been criticised for lacking practicability (Sahakian and Wilhite, 2014). Indeed, although empirical work exists, particularly in the energy demand field (Butler et al., 2014; Gram-Hanssen, 2010; Moloney and Strengers, 2014), this work tends not to use practice theory to produce interventions, but rather to critique them, such as the often-cited Cool Biz intervention (e.g. Sahakian and Wilhite, 2014; Shove, 2014; 
Shove et al., 2012), which reduced the energy demand from air conditioning by transforming the collective conventions around summer office wear in Japan.

Sahakian and Wilhite (2014) attempt to demonstrate how different pillars of a practice are brought into sustainable consumption activities such as introducing "unspoken norm[s] into public debate" or "by demonstrating different ways of performing everyday practices" (p.37). However, they recognise significant pitfalls in the theory's application, particularly in a policy context. The generally short-lived cycles of funding for behaviour change work requires swift and generally numeric evaluation, neither of which fit with an approach seeking to shift slowermoving conventions. Nonetheless, they go further than Shove (2014) in advocating how practice approaches could underpin intervention design. Shove limits an application of PT to an analysis of the problem, asking whether policy makers could "come up with a cross-sectoral analysis of how policy-making ... influences the texture and rhythm of daily life and the patterns of consumption on which such arrangements depend" (p.427). Redefining the problem is a vital first step, but Shove gives PT no further credit in the implementation of social change interventions. She reminds us that "social theories do not lead directly to prescriptions for action" (p.416). However, perhaps it is time to develop a framework for putting at least some of the insights from practice theory into 'real world' use.

\section{Contribution of social marketing: Towards a practice-based intervention planning process}

Social marketing is inherently applied with a focus on outcomes (French, 2009), and its 'Total Process Planning' model (Figure 1), is "widely accepted" (ibid, p.262). Taking this applied focus as our starting point, in contrast to the theoretical emphasis in social practice, we offer two additional unique contributions from social marketing, discussed below. In combination, these provide an opportunity for bringing practice theory into the real world of social change, and for social marketing to further its theoretical kudos, effectiveness and ambition.
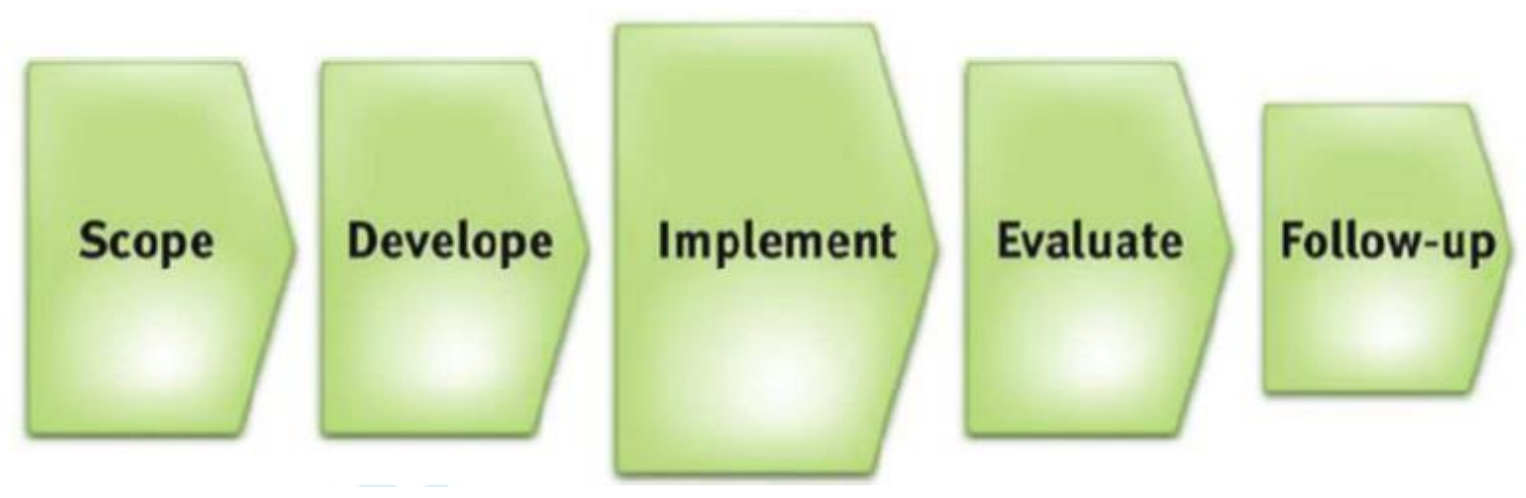

Figure 1: The Total Process Planning Model (French et al., 2010)

Firstly, although social marketers have been criticised for individualism, their preoccupation with what "moves and motivates" different segments (French, 2009, p.264) has been praised 
for underpinning programmes which fit within the flow of lifestyles and 'collective behaviour' (Barr, 2003). This expertise may support the recruitment of new practitioners to - and avoidance of their defection from - a recrafted or newly introduced practice entity. The performance of practice is generally important for its survival (Shove et al., 2012), often requiring "successive commitments of time, money, equipment and skill" (Reckwitz, 2002, p.259) and in many cases is "discretionary and ... defection is relatively easy" (Shove and Pantzar, 2007, n.p.). Indeed, far from being deterministic, practice theory allows for considerable agency both within individual practices, and in terms of engaging with some practices and not others (Welch, 2016). Therefore, deep insight into how performers experience a practice, and how a practice recruits and retains them, will be essential to a practice-based intervention planning process. Shove and Pantzar (2007), for example, found that interpersonal connections and 'the thrill of competition' could explain the ongoing commitment of team sports practitioners. Similarly, complex social patterns are important in the uptake and maintenance of smoking (Christakis and Fowler, 2008). The complexity of mechanisms within practices designed specifically to replace popular but unhealthy ones, such as home cooking to replace fast food consumption, will require careful audience research and insight generation. Social marketers are well placed to do this given the centrality of segmentation and deep insight to their work (Andreasen, 2002).

Secondly, social marketers have an innate understanding of markets and marketing systems and how to influence them, which Lefebvre (2011) argues should define their future focus. We add that this analysis of markets should form part of the preparatory ground in practicetheoretical intervention, and particularly when target practices (e.g. binge drinking, unhealthy snacking or unsustainable consumption) are bundled with the multifarious practices of corporate industries. Specifically, a practice-theoretical conceptualisation of the interrelationship between marketing systems and 'behaviour' offers a platform for interpreting markets as a "structural feature of a wider social system" (Giddens, 1984, p.24) which guides practitioners through the provision of material goods and associated images, but which are equally influenced and reconstituted through consumer agency. Multiple studies take this approach outside the social change agenda (Ingram et al., 2007; Szmigin et al., 2011; Wilhite, 2012), and we argue that social marketing can add significant value in unravelling the entanglement of market practices with everyday routines and exploring how to influence them.

This section now concludes with four key principles from practice theory. We then synthesise by combining these with the key contributions of social marketing to form the core of a practice-theoretical intervention planning process (P-TIPP).

Key principle 1: Interdisciplinarity

A practice-theoretical approach would not favour any specific path to social change, and practice-based interventions would be inherently interdisciplinary. Although unusual (Røpke, 
2009), interdisciplinary behaviour change has been identified as the key to future effectiveness (House of Lords, 2011). Interdisciplinarity is implied in the recommendations of Sahakian and Wilhite (2014), who warn against interventions focusing on only one aspect of a practice; and by Southerton and Welch (2015), who advocate tackling as full a range of the components of practices as possible. Furthermore, Røpke (2009) argues for 'collective efforts' across income distribution, energy prices and labour market institutions when tackling unsustainable energy consumption. Starting with an analysis of practice and bundles of practices which require resource, as Røpke suggests, will lead to a consideration of links between multiple elements (materials, meanings and competences), and then on to an interdisciplinary intervention design.

\section{Key principle 2: Focus on the practice, not the individual}

Practice theory views individuals as 'carriers' of practices (Schatzki et al., 2001) and the "unique crossing point of multiple practices" (Reckwitz, 2002, p.256). The unit of analysis is the practice (or bundle of practices) itself; the norms, conventions, ways of doing, know-how and requisite materials which make up the doing of a practice (Schatzki et al., 2001). As such, interventions planned within a practice-theoretical framework would first explore the full extent of the practices which underpin the social problems in question, whether commuter cycling or snacking, in order to identify how best to recraft or substitute them (Welch, 2016). This approach emphasises the wide context of how the problem activities are undertaken as part of social life, rather than simply seeing behaviour as an outcome from an individual's portfolio of attitudes and beliefs. This 'practice as entity' focus can then be combined with insights into the way that a practice is performed or reconstituted; why committed practitioners - the binge drinkers or smokers - are retained, or which wider institutional forces or competing practices might prevent this. By starting with the practice, this perspective "would turn attention away from blaming consumers and [for example] focus instead on the need for collective efforts to make consumption more sustainable" (Røpke, 2009, p.2497).

\section{Key principle 3: Ethnographic methods}

For the planning of practice-based social change interventions, ethnographic methods such as observation are recommended in combination with the interviewing methods hegemonic in social marketing (Truong, 2014). Scoping research to gain detailed insight into social problems is core in social marketing, as it is for practice theorists (Welch, 2016). However, given that the practice based approach foregrounds the routinisation of action and is based on the assumption that people live unreflexively in the spirit of their own lives (Bourdieu, 1977), many commentators have advocated ethnographic methods to look beyond people's articulated attitudes, which are often unstable and unhelpful as levers for change (e.g. Kollmuss and Agyeman, 2002; Mairesse et al., 2012). People's practical routines and the natural social interaction which is part of the re-negotiation of the 'rules of the game' governing those 
routines (Halkier and Jensen, 2011) should also be considered. Ethnography may also come into play for evaluation purposes, particularly because the bundling effects of practices can lead to unexpected consequences (Shove, 2014) and because shifting collective conventions may not be recognisable if measurement adopts traditional approaches (Hargreaves, 2011).

Key principle 4: Transforming collective conventions

The goal of practice-based social change would always be to transform the collective conventions of practice, rather than focus on shifting specific behaviours or attitudes:

"orientation should shift away from persuading, influencing and encouraging attitudinal change in the hope that millions of people will simultaneously change their behaviours, and towards a focus on how daily practices are co-ordinated and ordered within collective daily life" (Southerton et al., 2011a, p.34).

Uptake of a new behaviour may be an important part of practice change, but only a part. Collective conventions change when connections between elements of practice shift to such an extent that a practice becomes routinised. For example, a person can be enticed to recycle their takeaway cup, but the collective convention only changes when it no longer 'feels right' to sit in a café drinking coffee from a plastic cup, and when people doing so are unreflexively considered to be breaking socially agreed rules. To shift collective conventions, more than individual performances need to be targeted, such as the availability of alternatives and the nature of default options. In the long term, shifting collective conventions will have sustainable, wide-scale impact, should be the goal of social marketing activity and be reflected in its evaluation.

\section{Practice-theoretical intervention planning process (P-TIPP)}

Drawing on the Total Process Planning Model (Figure 1), we illustrate our theoretical ideas by introducing a social change intervention planning process underpinned by practice theory (Figure 2), which both moves away from a narrow individualist perspective and makes the best use of the particular strengths of social marketing.

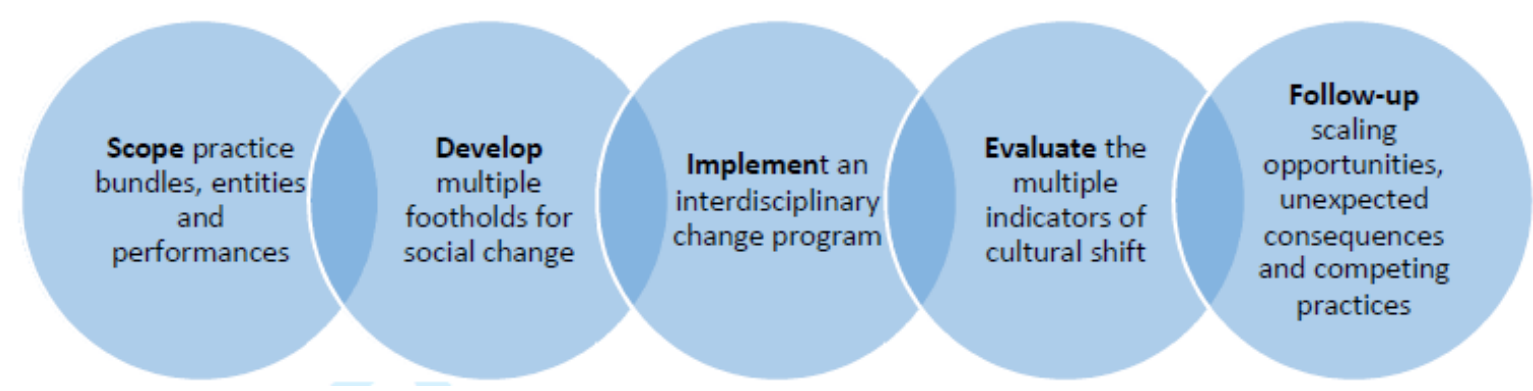

Figure 2: Practice-theoretical intervention planning process (P-TIPP) 


\section{Scope}

The social problem in question is scoped by first identifying and examining the practice entities and bundles which interplay in the formulation of the social problem by deploying the 3elements model or equivalent. As such, the entity of 'responsible drinking' (Fry, 2014) might be deconstructed into meanings, competences and materials. The collective conventions underpinning the target practice(s) are given particular attention; particularly in the way the elements interrelate. For example, there are material infrastructures that normalise 'stand up/vertical drinking' which are central to collective conventions entangled with binge drinking. Secondly the scoping exercise involves examining the experiences of practice performers to analyse how a practice is reconstituted by committed practitioners (for example, binge drinkers).

At a wider level, social institutions, organisations, regimes of power, discourse and networks of influence are reviewed to understand the contexts which lock the evolution of social practices into particular patterns (Welch, 2016). Notably, a focus is on understanding the dynamic interrelationships within the total market (Meadley et al., 2003), including "all of the actors in the marketing system or marketplace that determine who has access to what resources - at what costs and when" (Lefebvre, 2012, p.122). A mixed method research strategy is required, for example, deploying ethnography for 'practice performance' analysis alongside approaches to capture the interrelationships between performances and market systems, public discourses and institutional power dynamics.

Having achieved a "systematic analysis of the dynamic relation of practice elements to inform where ... changes are best made" (Welch, 2016, p.245), it is time to identify whether to recraft or substitute practice (ibid). For example, recrafting breakfast amongst lorry drivers to achieve healthier eating would involve introducing new materials at truck stops (e.g. porridge), competences (e.g. how to make porridge, and knowledge about its benefits) and meanings (e.g. porridge is delicious and sustaining, breakfast is an important meal for health and wellbeing, and it is normal to choose porridge over a fried option).

Another recrafting approach requires an examination of the way practices interlock through spatial and temporal routines, sequences and synchronisation (Southerton et al., 2011a). For example, the 'school run' involves a configuration of practices (driving, parking) which are locked into temporal patterns and create social problems, i.e. traffic congestion and pollution (Cass and Faulconbridge, 2016).

In contrast, taking a substitution approach involves identifying a practice to 'swap' for a problem practice. The practice of driving to work might be substituted for cycling. Here, there is a need to shift materials, competences and meanings of both the unhelpful practice and the 
competing, helpful practice. To do so, attention is given not just to individuals' attitudes but to infrastructural changes, including policy.

\section{Develop}

The scoping exercise identifies footholds for social change, which might include intervention tactics, positioning work, change strategies and partnerships, all of which are the remit of social marketers. The particular tactics for change would be developed within the practice context and be based on understandings about the ways practices change (e.g. Maller and Strengers, 2012; Shove et al., 2012). Broadly speaking, changes in practices occur through changes to the interconnections between any practice element, such as between material things and meanings, or competences and materials. For example, in addition to facilitating cycle storage, new cycle parking may help shift meanings around the normality of cycle commuting, in combination with softer measures. More recent work has identified more specifically that practices change through two mechanisms. Firstly, through the internal variations in performance, as practitioners engage differently with a practice (doings) and when they renegotiate its meanings through social interaction (sayings) (Warde, 2005). Thus development work would draw on rigorous performance insights and use the critical factors which motivate recruitment and retention (repeat performance) as intervention components. One example is the desire for social interaction amongst running club members, which can be used as an intervention component to recruit and retain runners.

Secondly, there are external mechanisms for change, which involves the imposed shifting or breaking of links between practice elements and/or bundles (Shove et al., 2012). Tasks required to achieve the appropriate practice/element changes involve developing or amending policies, legislation, education and materials, and also shifting competences and meanings. The goal of these is to recraft or substitute practices, and to do so social marketers must take a step back from their own expertise and consider what combination of intervention components is required, and what contribution social marketing can make. This transdisciplinary approach "transcend[s] separate conceptual, theoretical, and methodological orientations in order to develop a shared approach...building on a common conceptual framework" (Rosenfield, 1992, p.1351). Recognising the fundamental need for broad transdisciplinary and intersectoral working is essential to counter potential feelings of being daunted.

\section{Implement}

The implementation phase moves on from development to the managing of a project on the ground. Like most other social change projects, it involves working with a range of partners and stakeholders to implement the transdisciplinary program worked out on paper in earlier stages. Working alongside a range of stakeholders from different fields, agencies and disciplines brings 
with it cultural, communication and measurement problems, but is a route to innovation, creativity and effectiveness (Nash et al., 2003).

\section{Evaluate}

Rigorous evaluation is central to social change interventions to identify efficacy amongst behaviour change techniques (Michie et al., 2013). However, a practice-theoretical approach frames social change interventions in a different way to traditional approaches. As such the measurement of discrete behavioural shifts and 'single indicators' (Lefebvre, 2012), such as how many bowls of porridge have been sold in a truckers' café, are insufficient to gauge the effectiveness of a complex transdisciplinary program which aims to transform collective conventions around truckers' eating. In order to identify how practices are evolving, evaluation methodologies will need to acknowledge complexity (c.f. 'ReValuation' at http://www.cecan.ac.uk/) and commissioners of social change activity will need to embrace complex evidence around how collectively negotiated understandings, procedures and engagements (Warde, 2005) might be shifting in helpful directions, within both the practice of concern and a range of bundled practices. The goal is to evaluate how the intervention has shifted cultural patterns (Lefebvre, 2012), and as such ethnography is recommended. Hargreaves's (2011) ethnography demonstrates how observational insights into participants' talk can illuminate that more 'change' is occurring than would be picked up by traditional evaluation models. He writes that "exclusive focus on individuals' attitudes and values, or on the contextual 'barriers' to pro-environmental behaviours is too narrow to capture all that is involved in behaviour change interventions" (p.87).

We make three final points on evaluation. Firstly, a practice-theoretical evaluation might incorporate links between changes in spatial and temporal sequencing and practice change, and include evaluation of unexpected consequences. Secondly, given that policy and infrastructure changes are more likely to form part of an intervention than in 'traditional' exclusively downstream interventions, longitudinal and longer term evaluation studies are likely to be required. Finally, we note that not all elements of an intervention should be expected to be amenable to evaluation, but that this should not prohibit them from being undertaken if they can be demonstrated to be likely to play an important role in social change.

\section{Follow-up}

Follow-up involves analysing an intervention for learning and opportunities for scaling up. A social marketing follow-up is generally concerned with the comparison of local/case-specific evaluation criteria with broader (e.g. national) evaluation criteria, and with sharing best practice with relevant stakeholders such as funders and commissioners. As such the focus moves away from the behaviour itself to a process of systematising change at a level which might include corporate, institutional, policy and infrastructural change; all of which lie within 
the remit of a more broadly envisioned, critical notion of social marketing (Gordon et al., 2010). Within a practice approach, this would be an important part of follow-up but it would also include monitoring the evolution of practices and bundles once intervention activities have ceased. This would require watching for the sustainability/durability of introduced practices, scanning the environment for new practices which might poach recruited practitioners, and monitoring unexpected consequences (Shove, 2012). Thus, the focus remains on the wider evolution of practice bundles and not only on the systematisation of the intervention.

\section{Discussion}

Within the practice-theoretical approach to social change sketched out here, we propose, as Lefebvre (2012) does, to take the parts of social marketing "that have proven themselves useful in both research and practice and add to them current knowledge from related fields in order to make positive progress in how we use marketing for social change" (p.119). For example, whilst social marketing expertise is unrivalled in terms of generating audience insight, and in unravelling the impact of market systems, the conceptual framing of these contributions would be different. Practices, not people, would be the unit of analysis - and the focus of social change - with the ambition of shifting collective conventions around problematic and desirable practices rather than achieving less sustainable changes to discrete behaviours. We advocate this approach as a way of bringing social marketing up to speed with the innovative theoretical work being accomplished in the sustainable consumption, pro-environmental, energy reduction and mobility arenas but also to demonstrate social marketing's unique contribution.

The P-TIPP is, as yet, untested, although it is hoped this paper will form the basis for a new stream of activity which broadens the scope of social marketing and draws on the key concepts of practice theory for societal gain. There are inherent limitations to the proposed approach, however. The first is the difficulty in sometimes identifying the practice or bundles of practices which underpin societal problems (Warde, 2014). The second is the feasibility, within most intervention timescales and budgets, of achieving the rigorous evaluation described. The third is that new approaches are often difficult to effectively disseminate in both academia and policy circles.

Finally, we note that the notion of 'voluntary behaviour change' as a basic tenet of social marketing (Andreasen, 2002) is unhelpful within a practice-theoretical approach which foregrounds the routinised, unreflexive nature of patterns of behaviour performed by carriers of practice. Although it is acknowledged that social marketing may have emphasised 'voluntary' to position itself away from 'coercive' approaches, in practice-theoretical terms a notion of voluntariness over-emphasises individual choice rather than allowing for choice to be understood as intertwined with social and physical structures. People do not act outside these structures, and neither are they "judgmental dopes" (Reckwitz, 2002, p.256). Rather, 'behaviour' is both the manifestation of socio-cultural structure (practice entities) and the route 
of its reproduction (through performance), and within such a perspective, a notion of 'voluntary' is found to be fundamentally lacking.

\section{Conclusion}

Given the sheer scale and global reach of the problems that we now face (obesity, climate change, air pollution, poor mental health) it is easy for social marketers to succumb to a sense of paralysis and to take refuge in familiar approaches and ways of responding, even if we know these lack impact. This paper has argued that it is time to seek out the permeable walls between approaches to social change (Lefebvre, 2012). Despite social marketing's tendency to focus on individual behaviour change, and social practice theory's lack of application, both are driven by an ambition to effect changes in behaviour for the social good. We have, therefore, argued for a middle-way, which can harness the potential of both and offer a starting point for future projects aiming for rigorous and effective behaviour change at a social and cultural level.

\section{References}

Andreasen, A. (2002), "Marketing social marketing in the social change marketplace", Journal of Public Policy and Marketing, Vol.21 No.1, pp.3-13.

Arnott, B., Rehackova, L., Errington, L., Sniehotta, F.F., Roberts, J.R. and Araujo-Soares, V. (2014), "Efficacy of behavioural interventions for transport behaviour change: Systematic review, meta-analysis and intervention coding", International Journal of Behavioral Nutrition and Physical Activity, Vol.11 No.1, pp.133-156.

Bambra, C., Gibson, M., Sowden, A., Wright, K., Whitehead, M. and Petticrew, M. (2010), "Tackling the wider social determinants of health and health inequalities: evidence from systematic reviews", Journal of Epidemiology and Community Health, Vol.64 No.4, pp.284-291.

Barr, S. (2003), "Strategies for sustainability: Citizens and responsible environmental behaviour", Area, Vol.35 No.3, pp.227-240.

Blue, S., Shove, E., Carmona, C., and Kelly, M.P. (2016), "Theories of practice and public health: understanding (un)healthy practices", Critical Public Health, Vol.26 No.1. pp.36-50.

Bonsall, P. (2009), "Do we know whether personal travel planning really works?", Transport Policy, Vol.16 No.6, pp.306-314.

Bourdieu, P. (1977), Outline of a Theory of Practice, Cambridge University Press, Cambridge.

Butler, C., Parkhill, K.A. and Pidgeon, N.F. (2014), "Energy consumption and everyday life: choice, values and agency through a practice theoretical lens", Journal of Consumer Culture, Vol.0 No.0, pp.1-21. 
Cass, N. and Faulconbridge, J. (2016), "Commuting practices: new insights into modal shift from theories of social practice", Transport Policy, Vol.45, pp.1-14.

Chatterton, T. (2011), “An introduction to thinking about 'energy behaviour': a multi-model approach. A paper for the UK Department of Energy and Climate Change", available at http://tinyurl.com/jnnrumb (accessed 2 September 2016).

Chatterton, T. (2016), "An introduction to theories of behaviour", in Spotswood, F. (Ed.), Beyond Behaviour Change. Key Issues, Interdisciplinary Approaches and Future Directions, Policy Press, Bristol, pp.27-48.

Chatterton, T., Anable, J., Barnes, J. and Yeboah, G. (2016), “Mapping household direct energy consumption in the United Kingdom to provide a new perspective on energy justice", Energy Research and Social Science, Vol.18, pp.71-87.

Christakis, N.A. and Fowler, J.H. (2008), "The collective dynamics of smoking in a large social network", The New England Journal of Medicine, Vol.358 No.21, pp.2249-2258.

Crawshaw, P. (2013), "Public health policy and the behavioural turn: the case of social marketing", Critical Social Policy, Vol.33 No.4, pp.616-637.

Darnton, A. and Evans, D. (2013), The ISM Tool - a Technical Guide, Scottish Government, Edinburgh.

Darnton, A., Verplanken, B., White, P. and Whitmarsh, L. (2011), "Habits, routines and sustainable lifestyles: summary report. A research report completed for the Department for Environment, Food and Rural Affairs by AD Research and Analysis", available at http://tinyurl.com/hz4rtbj (accessed 2 September 2016).

DfT (2014), "Local area walking and cycling statistics: England 2012/13", available at http://tinyurl.com/q2cwogz (accessed 267 June 2014).

Domegan, C., McHugh, P., Devaney, M., Duane, S., Hogan, M., Broome, B.J., Layton, R.A., Joyce, J., Mazzonetto, M. and Piwowarczyk, J. (2016), "Systems-thinking social marketing: conceptual extensions and empirical investigations", Journal of Marketing Management, Vol.32 No.11-12, pp.1123-1144.

Evans, J. S. B. (2008), "Dual processing accounts of reasoning, judgment, and social cognition", Annual Review of Psychology, Vol.59, pp.255-278.

French, J. (2009), "The nature, development and contribution of social marketing to public health practice since 2004 in England", Perspectives in Public Health, Vol.129 No.6, pp.262-267.

French, J., Blair-Stevens, C., McVey, D. and Merritt, R. (2010), Social Marketing and Public Health. Theory and Practice, Oxford University Press, Oxford. 
Fry, M-L. (2014), "Rethinking social marketing: towards a sociality of consumption", Journal of Social Marketing, Vol.4 No.3, pp.210-222.

Giddens, A. (1984), The Constitution of Society, Polity Press, Cambridge.

Gordon, R., Moodie, C., Eadie, D. and Hastings, G. (2010), “Critical social marketing - the impact of alcohol marketing on youth drinking: qualitative findings", International Journal of Nonprofit and Voluntary Sector Marketing, Vol.15 No.3, pp.265-275.

Gram-Hanssen, K. (2010), "Standby consumption in households analyzed with a practice theory approach", Journal of Industrial Ecology, Vol.14 No.1, pp.150-165.

Griffin, C., Bengry-Howell, A., Hackley, C., Mistral, W. and Szmigin, I. (2009), "Every time I do it I absolutely annihilate myself': loss of (self-)consciousness and loss of memory in young people's drinking narratives", Sociology, Vol.43 No.3, pp.457-476.

Halkier, B. and Jensen, I. (2011), "Methodological challenges in using practice theory in consumption research. Examples from a study on handling nutritional contestations of food consumption", Journal of Consumer Culture, Vol.11 No.1, p.101-123.

Hargreaves, T. (2011), "Practice-ing behaviour change: applying social practice theory to proenvironmental behaviour change", Journal of Consumer Culture, Vol.11 No.1, pp.79-99.

Harrison, C. and Davies, G. (1998), "Lifestyles and the environment. Environment and sustainability desk study prepared for the ESRC", available at

http://www.psi.org.uk/ehb/docs/shove-changinghumanbehaviourandlifestyle-200308.pdf (accessed 16 August 2016).

Hastings, G. (2009), "Critical social marketing”, in Social Marketing and Public Health: Theory and Practice, French, J., Blair-Stevens, C., McVey, D. and Merritt, R. (Eds.). Oxford University Press, Oxford, pp.263-279.

Hastings, G. (2014), The Marketing Matrix: How the Corporation Gets Its Power - And How We Can Reclaim It, Routledge, Oxford.

Hobson, K. (2002), "Competing discourses of sustainable consumption: does the 'rationalisation of lifestyles' make sense?", Environmental Politics, Vol.11 No.2, pp.95-120.

House of Lords Science and Technology Select Committee, (2011), Behaviour Change. Report number: HL Paper 179, The Stationary Office Ltd., London.

Ingram, J., Shove, E. and Watson, M. (2007), "Products and practices: selected concepts from science and technology studies and from social theories of consumption and practice", Design Issues, Vol.23 No.2, pp.3-16. 
Kollmuss, A. and Agyeman, J. (2002), "Mind the gap: why do people act environmentally and what are the barriers to pro-environmental behavior?", Environmental Education Research, Vol. 8 No. 3, pp.239-260.

Lefebvre, R.C. (2011), "An integrative model for social marketing", Journal of Social Marketing, Vol.1 No.1, pp.54-72.

Lefebvre, R.C. (2012), "Transformative social marketing: co-creating the social marketing discipline and brand", Journal of Social Marketing, Vol.2 No.2, pp.118-129.

Leonard, S., Spotswood, F. and Tapp, A. (2012), "Overcoming the self-image incongruency of non-cyclists", Journal of Social Marketing, Vol.2 No.1, pp.23-36.

Lorenc, T., Petticrew, M., Welch, V. and Tugwell, P. (2013), "What types of interventions generate inequalities? Evidence from systematic reviews", Journal of Epidemiology and Community Health, Vol.67 No.2, pp.190-193.

Mairesse, O., Macharis, C., Lebeau, K. and Turcksin, L. (2012), "Understanding the attitudeaction gap: functional integration of environmental aspects in car purchase intentions", Psicologica: International Journal of Methodology and Experimental Psychology, Vol.33 No.3, pp.547-574.

Maller, C. and Strengers, Y. (2012), "The global migration of everyday life: investigating the practice memories of Australian migrants”, Geoforum, Vol.44, pp.243-252.

Marmot, M., Allen, J., Goldblatt, P., Boyce, T., McNeish, D., Grady, M. and Geddes, I. (2010), "The Marmot review: Fair society, healthy lives", available at http://www.instituteofhealthequity.org/projects/fair-society-healthy-lives-the-marmot-review (accessed 2 September 2016).

Meadley, J., Pollard, R. and Wheeler, M. (2003), Review of DFID Approach to Social Marketing, DFID Health Systems Resource Centre, London.

Michie, S., Richardson, M., Johnston, M., Abraham, C., Francis, J., Hardeman, W., Eccles, M.P., Cane, J. and Wood, C.E. (2013), "The Behavior Change Technique Taxonomy (v1) of 93 hierarchically clustered techniques: building an international consensus for the reporting of behavior change interventions", Annals of Behavioral Medicine, Vol.46 No.1, pp.81-95.

Moloney, S. and Strengers, Y. (2014). “'Going Green'?: The limitations of behaviour change programmes as a policy response to escalating resource consumption", Environmental Policy and Governance, Vol.24 No.2, pp.94-107.

Nash, J.M., Collins, B.N., Loughlin, S.E., Solbrig, M., Harvey, R., Krishnan-Sarin, S., Unger, J., Miner, C., Rukstalis, M., Shenassa, E., Dube, C. and Spirito, A. (2003), "Training the transdisciplinary scientist: a general framework applied to tobacco use behaviour", Nicotine and Tobacco Research, Vol.5 No.1, pp.s41-s53. 
Pulford J., Hetzel, M.W., Bryant, M., Siba, P.M. and Mueller, I. (2011), "Reported reasons for not using a mosquito net when one is available: a review of the published literature", Malaria Journal, Vol.10 No.1, pp.83-93.

Raftopoulou, E. and Hogg, M.K. (2010), "The political role of government-sponsored social marketing campaigns", European Journal of Marketing, Vol.44 No.7/8, pp.1206-1227.

Reckwitz, A. (2002), "Toward a theory of social practices: a development in culturalist theorizing", European Journal of Social Theory, Vol.5 No.2, pp.243-263.

Riley, S., Morey, Y. and Griffin, C. (2012), “The rise of the 'pleasure citizen': how leisure can be a site for alternative forms of political participation", in Demetriou, K. (Ed.), Democracy in Transition: Political Participation in the European Union, Springer, Berlin, pp.61-75.

Røpke, I. (2009), "Theories of practice - new inspiration for ecological economic studies on consumption", Ecological Economics, Vol.68 No.10, pp.2490-2497.

Rosenfield, P.L. (1992), “The potential for transdisciplinary research for sustaining and extending linkages between the health and social sciences", Social Science and Medicine, Vol.35 No.11, pp.1343-1357.

Sahakian, M. and Wilhite, H. (2014), "Making practice theory practicable: towards more sustainable forms of consumption", Journal of Consumer Culture, Vol.14 No.1, pp.25-44.

Schatzki, T., Cetina, K.K. and von Savigny, E. (2001), The Practice Turn in Contemporary Theory, Routledge, London.

Shove, E. (2010), "Social theory and climate change: questions often, sometimes and not yet asked", Theory, Culture and Society, Vol.27 No.2-3, pp.277-288.

Shove, E. (2012), "Habits and their creatures", in A. Warde and D. Southerton (eds), The habits of consumption, Vol.12, Collegium, Helsinki, pp.100-113.

Shove, E. (2014), "Putting practice into policy: reconfiguring questions of consumption and climate change", Contemporary Social Science, Vol.9 No.4, pp.415-429.

Shove, E. and Pantzar, M. (2007), "Recruitment and reproduction: the careers and carriers of digital photography and floorball", Journal of Human Affairs, Vol.17 No.2, n.p.

Shove, E., Pantzar, M. and Watson, M. (2012), The Dynamics of Social Practice: Everyday life and how it changes, Sage Publications, London.

Spotswood, F., Chatterton, T., Tapp, A. and Williams, D. (2015), “Analysing cycling as a social practice: an empirical grounding for behaviour change", Transport Research Part F, Vol.29, pp.22-33. 
Southerton, D., Diaz-Mendez, C. and Warde, A. (2011a), "Behavioural change and the temporal ordering of eating practices: a UK-Spain comparison", International Journal of Sociology of Agriculture and Food, Vol.19 No.1, pp.19-36.

Southerton, D., McMeekin, A. and Evans, D. (2011b), "International review of behaviour change initiatives", available at http://tinyurl.com/hareh6x (accessed 1 July 2015).

Southerton, D. and Welch, D. (2015), "A social practice perspective", in Christmas, S., Michie, S. and West, R. (Eds.), Thinking About Behaviour Change: An Interdisciplinary Dialogue, Silverback Publishing, London.

Spaargaren, G. (2003), "Sustainable consumption: a theoretical and environmental policy perspective", Society and Natural Resources, Vol.16 No.8, pp.687-701.

Szmigin, I., Bengry-Howell, A., Griffin, C., Hackley, C. and Mistral, W. (2011), "Social marketing, individual responsibility and the "culture of intoxication"”, European Journal of Marketing, Vol.45 No.5, pp.759-779.

Thwing J., Hochberg, N., Vanden Eng J., Issifi, S., Eliades, M.J., Minkoulou, E., Wolkon, A., Gado, H., Ibrahim, O., Newman, R.D. and Lama, M. (2008), "Insecticide-treated net ownership and usage in Niger after a nationwide integrated campaign", Tropical Medicine and International Health, Vol.13 No.6, pp.827-834.

Truong, V. D. (2014), "Social marketing: a systematic review of research 1998-2012", Social Marketing Quarterly, Vol.20 No.1, pp.15-34.

Tsang, F., Burge, P., Chatterton, T., Wilson, C., Diepeveen, S., Guerin, B., Drabble, S. and Bloom, E. (2012), "What works in changing energy-using behaviours in the home? A rapid evidence assessment. Undertaken by RAND Europe", available at http://tinyurl.com/j4dqysx (accessed 2 September 2016).

Vihalemm, T.; Keller, M.; Kiisel, M. (2015), From intervention to social change: A guide to reshaping everyday practices, Ashgate Publishing, Farnham.

Warde, A. (2005), "Consumption and theories of practice", Journal of Consumer Culture, Vol.5 No.2, pp.131-153.

Warde, A. (2014), "After taste: culture, consumption and theories of practice", Journal of Consumer Culture, Vol.14 No.3, pp.279-303.

Warde, A., Cheng, S-L., Olsen, W. and Southerton, D. (2007), "Changes in the practice of eating: a comparative analysis of time-use", Acta Sociologica, Vol.50 No.4, pp.363-385.

Watson, M. (2016), "Placing Power in Practice Theory", in The Nexus of Practices: Connections, constellations and practitioners, A. Hui, T. Schatzki and E. Shove (eds), Routledge, London. 
Welch, D. (2016), "Social practices and behaviour change", in Spotswood, F. (Ed.), Beyond Behaviour Change. Key Issues, Interdisciplinary Approaches and Future Directions, Policy Press, Bristol, pp.237-256.

Wilhite, H.L. (2012), "Towards a better accounting of the roles of body, things and habits in consumption", Collegium: Studies across Disciplines in the Humanities and Social Sciences. Vol.12, pp.87-100.

Wilson, C. and Chatterton, T. (2011), "Multiple models to inform climate change policy: a pragmatic response to the 'beyond the $A B C$ ' debate", Environment and Planning A, Vol.43 No.12, pp.2781-2787. 